\title{
Technical note: p40 antibody as a replacement for p63 antibody in bovine mammary immunohistochemistry
}

\author{
C. L. M. Parsons, H. L. M. Tucker, R. M. Akers, ${ }^{1}$ and K. M. Daniels \\ Dairy Science Department, Virginia Polytechnic Institute and State University, Blacksburg 24061
}

\begin{abstract}
Tumor protein 63 (p63) is a nuclear antigen found in basal epithelial cells. To date, 10 isoforms of p63 have been identified, falling into 2 major groups identified by presence or absence of an N-terminal transactivation domain (TAp63 and $\Delta \mathrm{Np} 63$, respectively). Literature suggests that $\Delta \mathrm{Np} 63$ is the predominant form expressed in basal epithelial cells and myoepithelial cells (MYEC). The mouse anti-p63 antibody, clone 4B1E12, has been used as a specific nuclear marker for bovine MYEC. Unfortunately, this antibody is no longer commercially available. A new mouse monoclonal antibody, clone $\mathrm{BC} 28$, specific to $\Delta \mathrm{Np} 63$ (designated p40) has been developed. We hypothesized that the p40 antibody would be an appropriate substitution as a MYEC and epithelial basal cell marker. An array of archived formalin-fixed, paraffin-embedded bovine tissues were subjected to immunohistochemical staining for either p40 or p63, with a subset being dual stained for direct comparison. Positive staining for p40 and p63 was observed in serial sections of mammary, skin, rumen, salivary gland, ureter, and bladder. As predicted, negative staining for p40 and p63 was observed in testis and intestine. Dual staining for p40 and p63 in calf mammary $(\mathrm{n}=4)$, lactating mammary $(\mathrm{n}=4)$, rumen ( $\mathrm{n}$ $=4)$, and skin $(\mathrm{n}=4)$ showed nearly $100 \%$ agreement. Thus, we established that the mouse monoclonal antibody, clone $\mathrm{BC} 28$, is a suitable replacement for antip63, clone 4B1E12, as a marker of MYEC and basal epithelial cells in bovine tissues.
\end{abstract}

Key words: mammary, myoepithelial, p63, p40

\section{Technical Note}

Tumor protein 63, also known as transformation-related protein 63 (p63), is a structural homolog of tumor protein p53. The gene has 2 promotors, which generate

Received March 1, 2018.

Accepted March 30, 2018.

${ }^{1}$ Corresponding author: rma@vt.edu
$2 \mathrm{~N}$-terminal variants, one containing a transactivation domain (TAp63) and one without $(\Delta \mathbf{N p 6 3})$. Additional splice variations give rise to 5 different $\mathrm{C}$-termini $(\alpha, \beta, \gamma, \delta, \varepsilon)$ for a total of 10 possible isoforms (Guerrini et al., 2011; Nobre et al., 2013). The TAp63 protein transactivates p53 target genes and induces apoptosis (Di Como et al., 2002), whereas $\Delta$ Np63 acts in a dominant negative manner to block transactivation. It is known that $\Delta \mathrm{Np} 63$ also has specific transcriptional activities through a second small transactivation domain. (Browne et al., 2011; Guerrini et al., 2011; Nobre et al., 2013).

The importance of p63 in embryonic development is difficult to overstate. Mouse p63 double knock-out models demonstrated severe craniofacial, limb, and epithelial defects, with limb truncation and lack of epidermis. These animals died shortly after birth and demonstrated a lack of all squamous epithelia and derivatives, including mammary, lachrymal, and salivary glands (Yang et al., 1999). Thus, p63 protein serves a dual function: enabling terminal differentiation and stratification of epidermal cells by allowing cells to escape the stem state and cell cycle, and maintenance of the proliferative capacity of epidermal stem/progenitor cell populations (Guerrini et al., 2011; Nobre et al., 2013). Postnatal epidermal expression of p63 occurs in the basal nuclei of normal epithelia (skin, esophagus, tonsil, urogenital tract) as well as glandular epithelial structures such as salivary, mammary, and prostate glands (Guerrini et al., 2011; Nobre et al., 2013). Stratified epithelium expresses p63 basally and within 1 or 2 supra-basal cell layers (Hall et al., 2000). Basal cells predominantly express $\Delta \mathrm{Np} 63$ (about 100 -fold to TAp63), whereas cells in upper layers of stratified epithelia express TAp63 (Nobre et al., 2013).

Myoepithelial cells (MYEC) are located in the basal cell layer of normal mammary epithelia. Moreover, p63 has been found to be a selective nuclear marker of MYEC in the human breast (Barbareschi et al., 2001), alone or in combination with cytoplasmic markers such as smooth muscle myosin heavy chains, calponin, P-cadherin, mapsin, CD10, and smooth muscle actin (Barbareschi et al., 2001; Dewar et al., 2011). We have 
Table 1. Primary and secondary antibodies used in this experiment

\begin{tabular}{|c|c|c|}
\hline Item & $\mathrm{p} 63$ & $\mathrm{p} 40$ \\
\hline Host, serotype & Mouse, $\operatorname{IgG}_{2 \mathrm{~b}}$ & Mouse, $\mathrm{IgG}_{1}$ \\
\hline Source & No. 37-9500 Invitrogen, Waltham, MA & No. A21141 Abcam Inc., Cambridge, MA \\
\hline \multicolumn{3}{|c|}{ Secondary antibody } \\
\hline Host, conjugate & Goat, Alexa 488 & Goat, Alexa 594 \\
\hline Serotype & Anti- Mouse $\operatorname{IgG}_{2 \mathrm{~b}}$ & Anti-Mouse $\operatorname{IgG}_{1}$ \\
\hline
\end{tabular}

used cytoplasmic markers smooth muscle actin and CD10, with or without p63, to identify and characterize MYEC in bovine mammary tissue (Safayi et al., 2012; Tucker et al., 2016). It is challenging to identify primary antibodies that are specific for, or cross-react successfully with, bovine antigens. Tucker et al. (2016) used a mouse anti-p63, clone 4B1E12 (No. 37-9500; Invitrogen, Waltham, MA) to label MYEC nuclei. This antibody was also successful in labeling basal cells of bovine skin and rumen epithelium (K. M. Daniels, unpublished data). Unfortunately, the manufacturer has discontinued this product.

Recently, human cancer diagnostic research has explored the use of primary antibodies specific to the $\Delta \mathrm{Np} 63$ isoform (p40) versus traditionally used anti-p63 antibodies (such as clone 4A4), which recognize both TAp63 and $\Delta$ Np63 isoforms (Nobre et al., 2013; Tacha et al., 2014). We chose mouse monoclonal p40 (clone BC28) from Abcam (ab172731; Abcam Inc., Cambridge, MA) to compare with our remaining stock of mouse anti-p63 (clone 4B1E12) in identifying MYEC and other epithelial basal cell nuclei in an array of bovine tissues. We hypothesized that the p40 antibody would identify the same cell nuclei as the existing p63 antibody. Further, we hypothesized that the p40 antibody would improve specificity of basal cell identification in stratified epithelium, as $\Delta \mathrm{Np} 63(\mathrm{p} 40)$ is suggested to be the dominant isoform in these cells (Nobre et al., 2013). According to the manufacturer (see Table 1), the p63 antibody was raised against a recombinant protein derived from the N-terminal region of human p63 (suggesting TAp63 or total p63), which would likely label more supra-basal epithelial cells.

Archived formalin-fixed, paraffin-embedded bovine tissues were used in this experiment. All tissues originated from animals enrolled in previously approved animal care and use protocols at Virginia Tech (DASC 14-045, 15-165). Samples of calf and lactating cow mammary parenchyma $(\mathrm{n}=4)$, calf rumen $(\mathrm{n}=4)$, and calf ear skin $(n=4)$ were dual immunofluorescently stained with p40 and p63 antibodies for direct comparison. Single samples representing other calf epithelial tissues were also stained with each antibody for presence or absence of labeled cells.

Table 2. Description of p63 and p40 in normal bovine tissues by immunohistochemistry

\begin{tabular}{|c|c|c|c|c|}
\hline Organ site & p63 Score $^{1}$ & p40 Score $^{1}$ & Number of animals & Cells dual labeled ${ }^{2}(\%$ of total) \\
\hline Rumen & $(++)$ & $(++)$ & 4 & $97.4 \pm 1.1$ \\
\hline \multicolumn{5}{|l|}{ Urinary system } \\
\hline Bladder & $(++)$ & $(++)$ & 1 & $\mathrm{~N} / \mathrm{A}$ \\
\hline \multirow{2}{*}{\multicolumn{5}{|c|}{ Reproductive system }} \\
\hline & & & & \\
\hline Testis & $(-)$ & $(-)$ & 1 & $\mathrm{~N} / \mathrm{A}$ \\
\hline \multicolumn{5}{|l|}{ Skin } \\
\hline Epidermis & $(++)$ & $(++)$ & 4 & $98.1 \pm 0.7$ \\
\hline Hair follicles & $(++)$ & $(++)$ & & $\mathrm{N} / \mathrm{A}$ \\
\hline Sweat glands & $(++)$ & $(++)$ & & $\mathrm{N} / \mathrm{A}$ \\
\hline Tonsil & $(++)$ & $(++)$ & 1 & $\mathrm{~N} / \mathrm{A}$ \\
\hline Salivary gland & $(++)$ & $(++)$ & 1 & $\mathrm{~N} / \mathrm{A}$ \\
\hline
\end{tabular}

${ }^{1}(-)=$ undetectable $;(+)=$ moderate $;(++)=$ strong.

${ }^{2}$ Data given as mean \pm SEM.

${ }^{3} \mathrm{~N} / \mathrm{A}=$ not quantified for $\%$ agreement. 
Serial sections, $5-\mu \mathrm{m}$ thick, were cut from paraffinembedded tissue blocks. Two to 4 serial sections were mounted on positively charged microscope slides. The immunohistochemistry protocol is described previously (Tucker et al., 2016). Briefly, slides were deparaffinized, rehydrated, and antigens retrieved in $10 \mathrm{~m} M$ citrate buffer $\mathrm{pH} 6.0$ at 90 to $95 \mathrm{C}^{\circ}$. Individual tissue sections were isolated using PAP pen (No. 22311, Ted Pella Inc., Redding, CA), and blocked with CAS Block (Life Technologies Corp., Grand Island, NY).

Primary antibodies were diluted in CAS Block: p63 at 1:200 (No. 37-9500, Invitrogen, Waltham, MA) and p40 at 1:100 (ab172731, Abcam Inc.). Further details describing these antibodies are in Table 1. Dual staining with both p40 and p63 was accomplished by adding both antibodies to a single volume of diluent while maintaining stated dilutions. Individual sections received either a set volume of primary antibody solution or an equal volume of CAS Block (negative control). Slides were incubated overnight at $4^{\circ} \mathrm{C}$ in a humidified chamber. Primary antibody solution was removed and sections washed with PBS. All tissue sections, including negative controls, received equal volumes of isotypespecific, fluorophore-conjugated antibody diluted 1:200 in CAS Block (Table 1). Slides were incubated for 60 min at room temperature.

Coverslips were mounted using SlowFade Gold antifade reagent with $4^{\prime}, 6$-diamidino-2-phenylindole (DAPI; S36939, Invitrogen, Eugene, OR), and slides were allowed to cure $24 \mathrm{~h}$ before viewing. Digital images were acquired using a Nuance FX multispectral imaging system (Perkin Elmer Inc., Waltham, MA)
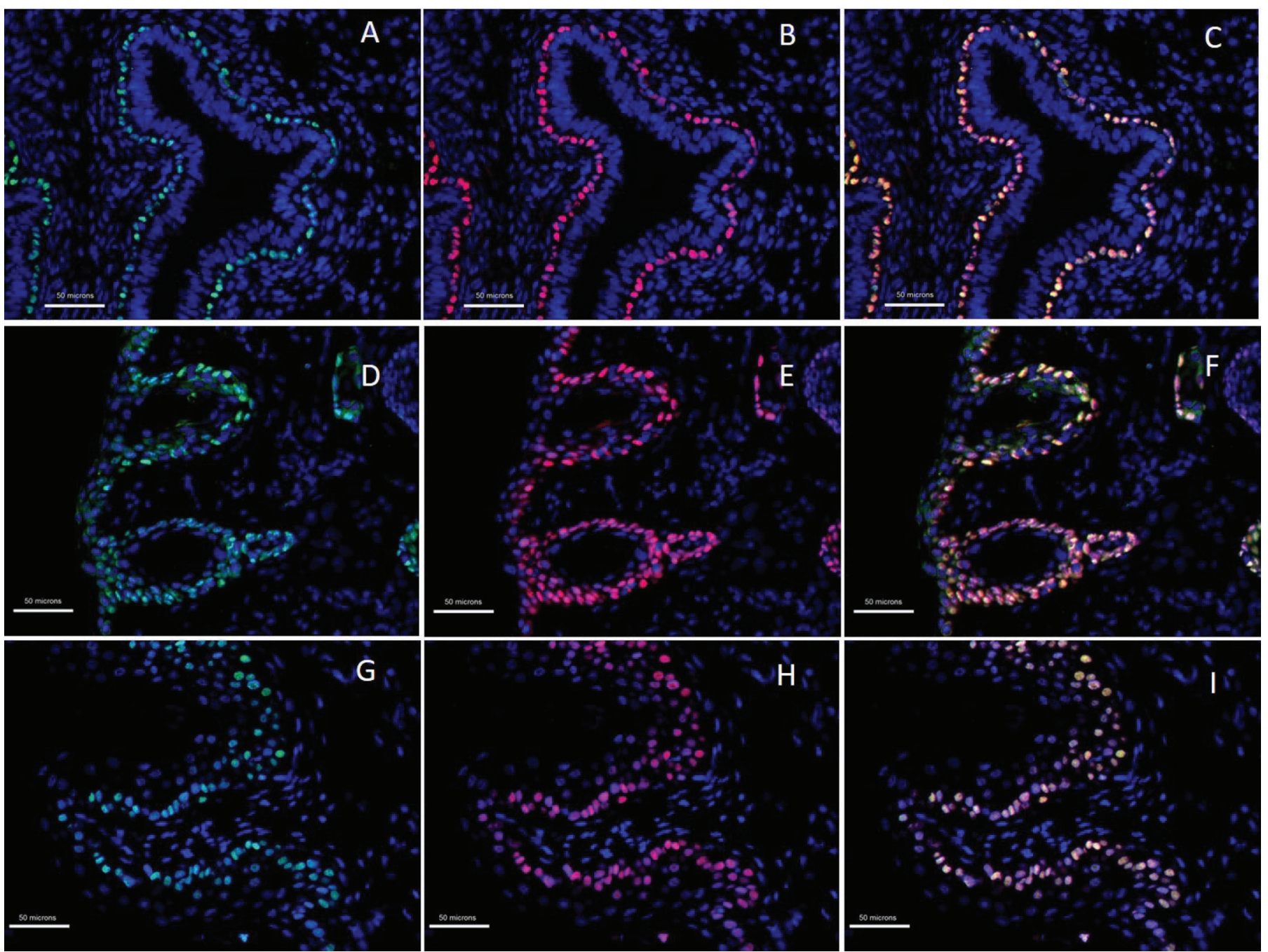

Figure 1. Images illustrating immunostaining for tumor protein (p63, green) positive nuclei (A, D, G), tumor protein ( $\mathrm{p} 40$, red) positive nuclei (B, E, H), and dual labeling of p63 and p40 (C, F, I), in calf mammary (A-C), calf ear skin (D-F), and calf rumen (G-I). Staining with $4^{\prime}, 6$-diamidino-2-phenylindole (DAPI, blue) indicates all cell nuclei. Scale bar is $50 \mu \mathrm{m}$. 
mounted on a Nikon Eclipse E600 (Nikon, Tokyo, Japan) epi-fluorescence microscope that was fitted with $20 \times$ and $40 \times$ objectives, as described in Tucker et al. (2016).

Images for dual-stained sections of skin, rumen, and calf and lactating mammary were acquired using the $40 \times$ objective, and layered composite images (red, green, blue) were created using ImagePro Plus, version 7.0 (Media Cybernetics, Silver Spring, MD). Color component images (p63: green, p40: red, nuclei: blue) were displayed individually to enumerate positively stained nuclei. The software provides the ability to toggle back and forth between the color component images (essentially turning each color in the image on or off), which allows marking of nuclei in each color channel within the same fields of view. Sums of p63-positive, p40-positive, and dual-labeled nuclei were generated for each of the 2 images per slide. Sections from samples of other epithelial tissues (salivary gland, bladder, ureter, tonsil, testis, and intestine) were single-stained for either p63 or p40, and sections were identified as being positive or negative for staining with each antibody. Both p40 and p63 stained nuclei (in similar locations and quantities) in the single samples of salivary gland, tonsil, bladder and ureter, whereas testis and intestine were negative for both (Table 2). Dual-stained tissues of skin, rumen, and calf and lactating mammary exhibited positively stained nuclei for both p63 and p40 (nearly 100\% agreement $98.1 \pm 1.7 \%$ overall).

The high degree of agreement between p40 and p63 dual-stained nuclei validates our hypothesis that the mouse monoclonal antibody to p40 (clone BC28) will be a good replacement for the existing p63 antibody (Figure 1). Additionally, our survey of other epithelial tissues supports findings in human tissues (Di Como et al., 2002) and confirms that p40 is a useful tool to identify basal epithelial nuclei in bovine tissues. We did not observe a marked difference in either p40 or p63 staining intensity from basal to supra-basal cells in the stratified epithelium of skin and rumen; thus, the new p40 antibody did not improve specificity of basal cell identification. This is not entirely surprising given that the p63 antibody product information does not provide isoform specificity. Product literature stated that the antibody identified an approximately $70-\mathrm{kDa}$ band in human A431 cell lysates by Western blot. There are 2 p63 isoforms close to $70 \mathrm{kDa}$ in size: TAp63e (68 $\mathrm{kDa})$ and $\Delta \mathrm{Np} 63 \alpha(66 \mathrm{kDa})$. Basal cells of stratified epithelium express $\Delta \mathrm{Np} 63 \alpha$ (Nobre et al., 2013); therefore, it is reasonable to expect that the p63 antibody is identifying $\Delta \mathrm{Np} 63$, as is the p40 antibody. We judge both antibodies to have equivalent value in identifying basal epithelial cell nuclei.

\section{ACKNOWLEDGMENTS}

The authors acknowledge support from multiple grants with colleagues including NRI USDA grants 2006-35206-15599, 2009-35208-05778 and most recently USDA-National Institute of Food and AgricultureAgriculture and Food Research Initiative, 2016-6701524575, Impact of Pre-Weaning Nutrition on Endocrine Induction of Mammary Development in Dairy Heifers.

\section{REFERENCES}

Barbareschi, M., L. Pecciarini, M. G. Cangi, E. Macrì, A. Rizzo, G. Viale, and C. Doglioni. 2001. p63, a p53 homologue, is a selective nuclear marker of myoepithelial cells of the human breast. Am. J. Surg. Pathol. 25:1054-1060.

Browne, G., R. Cipollone, A. M. Lena, V. Serra, H. Zhou, H. van Bokhoven, V. Dötsch, D. Merico, R. Mantovani, A. Terrinoni, R. A. Knight, E. Candi, and G. Melino. 2011. Differential altered stability and transcriptional activity of $\Delta \mathrm{Np} 63$ mutants in distinct ectodermal dysplasias. J. Cell Sci. 124:2200-2207. https://doi.org/ $10.1242 /$ jcs.079327.

Dewar, R., O. Fadare, H. Gilmore, and A. M. Gown. 2011. Best practices in diagnostic immunohistochemistry: Myoepithelial markers in breast pathology. Arch. Pathol. Lab. Med. 135:422-429.

Di Como, C. J., M. J. Urist, I. Babayan, M. Drobnjak, C. V. Hedvat, J. Teruya-Feldstein, K. Pohar, A. Hoos, and C. Cordon-Cardo. 2002. p63 expression profiles in human normal and tumour tissues. Clin. Cancer Res. 8:494-501.

Guerrini, L., A. Costanzo, and G. R. Merlo. 2011. A symphony of regulations centered on p63 to control development of ectodermderived structures. J. Biomed. Biotechnol. 2011:864904. https:// doi.org/10.1155/2011/864904.

Hall, P. A., S. J. Campbell, M. O'Neill, D. J. Royston, K. Nylander, F. A. Carey, and N. M. Kernohan. 2000. Expression of the p53 homologue p63alpha and deltaNp63 alpha in normal and neoplastic cells. Carcinogenesis 21:153-160.

Nobre, A. R., A. Albergaria, and F. Schmitt. 2013. p40: A p63 isoform useful for lung cancer diagnosis - a review of the physiological and pathological role of p63. Acta Cytol. 57:1-8. https://doi.org/10 $.1159 / 000345245$.

Safayi, S., N. Korn, A. Bertram, R. M. Akers, A. V. Capuco, S. L. Pratt, and S. Ellis. 2012. Myoepithelial cell differentiation markers in prepubertal bovine mammary gland: effect of ovariectomy. J. Dairy Sci. 95:2965-2976.

Tacha, D., R. Bremer, T. Haas, and W. Qi. 2014. An immunohistochemical analysis of a newly developed, mouse monoclonal p40 (BC28). Arch. Pathol. Lab. Med. 138:1358-1364.

Tucker, H. L. M., K. L. Beaudry, C. L. M. Parsons, S. E. Ellis, and R. M. Akers. 2016. Impaired mammary development in tamoxifentreated prepubertal heifers is associated with altered development and morphology of myoepithelial cells. J. Dairy Sci. 99:1009310101.

Yang, A., R. Schweitzer, D. Sun, M. Kaghad, N. Walker, R. T. Bronson, C. Tabin, A. Sharpe, D. Caput, C. Crum, and F. McKeon. 1999. p63 is essential for regenerative proliferation in limb, craniofacial and epithelial development. Nature 398:714-718. 